\title{
Echocardiographic Features of Right Ventricular Cavernous Hemangioma: A Rare Case
}

\author{
Xiaoyan Chen ${ }^{1}$, Jianxiu Fang ${ }^{1}$, Qingmei Yang ${ }^{1}$, and Haifeng Guo ${ }^{1}$
}

${ }^{1}$ Affiliation not available

October 23, 2020

\begin{abstract}
Cardiac cavernous hemangiomas are rare primary tumors of the heart. Echocardiography can determine their size, morphology, location, and mobility, and the compression caused by them. We here present a case of a 41-year-old woman with atypical chest discomfort of 2 months duration and display her echocardiographic images. Final postoperative histopathological examination of the surgical specimen confirmed cavernous hemangioma of the right ventricle. In this rare case, we have described the echocardiographic features of a cavernous hemangioma involving the right ventricle.
\end{abstract}

\section{Hosted file}

manuscript - ECHO.pdf available at https://authorea.com/users/369642/articles/488447echocardiographic-features-of-right-ventricular-cavernous-hemangioma-a-rare-case 

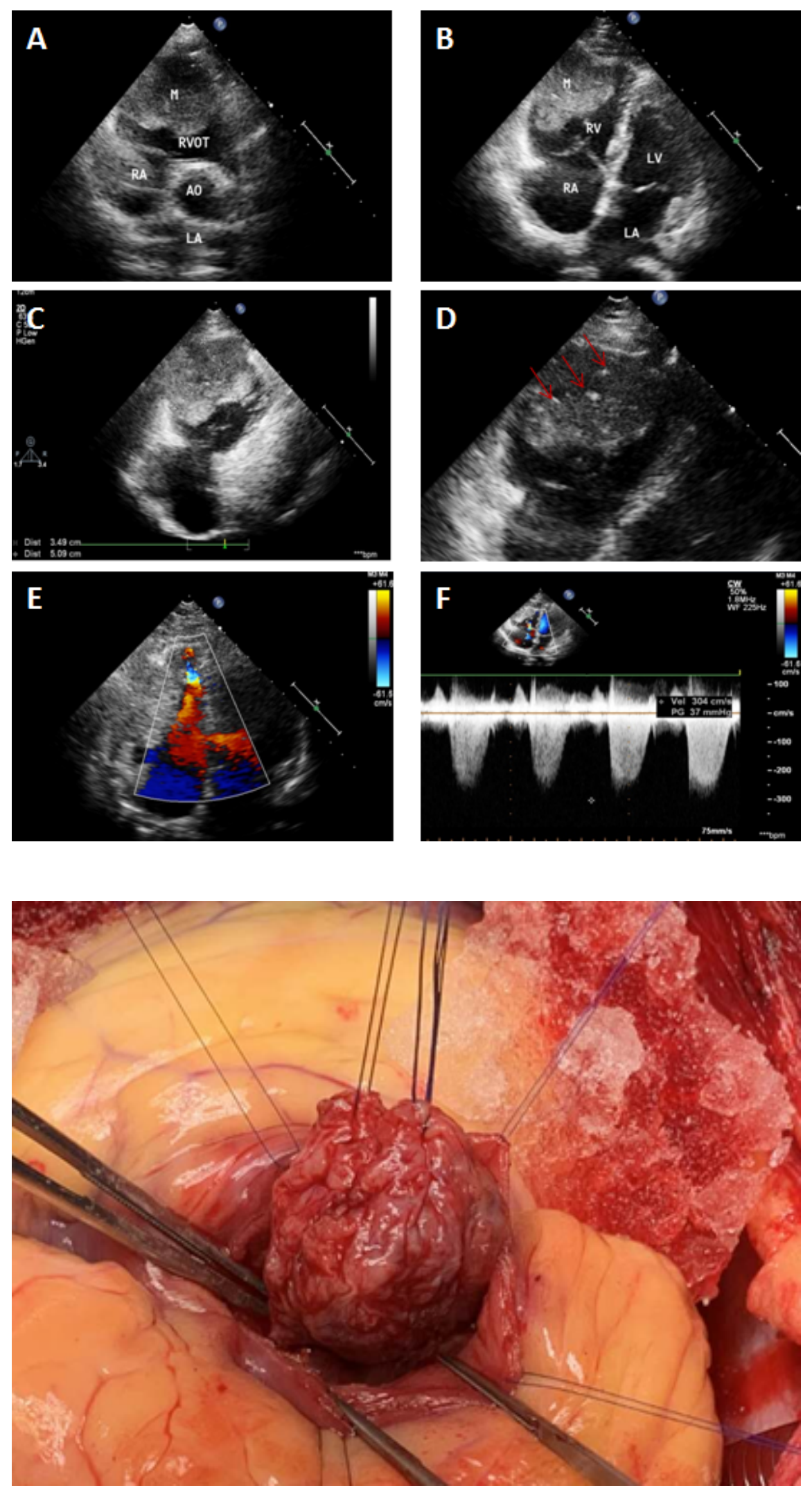